\title{
Lawn and Garden Equipment Sound: A Comparison of Gas and Battery Electric
}

\section{Equipment}

\author{
Chris Pollock ${ }^{1}$, Geoffrey Sparks ${ }^{2}$ and Jamie L Banks ${ }^{3 *}$ \\ ${ }^{1}$ Arup, Inc., 77 Water St, New York, NY, USA \\ ${ }^{2}$ Arup, Inc., 1120 Connecticut Ave NW, Washington, DC, USA \\ ${ }^{3}$ Quiet Communities, P.O. Box 533, Lincoln, MA, USA
}

*Corresponding author: Jamie L Banks, Quiet Communities, P.O. Box 533, Lincoln, MA, 01773, USA, E-mail: jlbanks@quietcommunities.org

Received: 30 Oct, 2018 | Accepted: 27 Nov, 2018 | Published: 04 Dec, 2018

Citation: Pollock C, Sparks G, Banks JL (2018) Lawn and Garden Equipment Sound: A Comparison of Gas and Battery Electric Equipment. J Environ Toxicol Stud 3(1): dx.doi.org/10.16966/2576-6430.118

Copyright: (c) 2018 Pollock C, et al. This is an open-access article distributed under the terms of the Creative Commons Attribution License, which permits unrestricted use, distribution, and reproduction in any medium, provided the original author and source are credited.

\begin{abstract}
Noise from gas-powered leaf blowers (GLBs) has become a source of distress for communities in North America and around the world. To date, approximately 170 communities in the United States have enacted regulations aimed at restricting their use. Battery electric leaf blowers (BLBs) have been suggested as a quieter alternative, but there are no published scientific studies comparing their sound to GLBs. This study compares directly the operating characteristics of measured sound $\left(L_{90}\right)$ from leading models of commercial GLBs and BLBs and includes a GLB with the same manufacturer sound rating as two of the BLBs ( $65 \mathrm{dBA}$ at 50 feet). $L_{90}$ levels at five feet ranged from 72 to $90 \mathrm{dBA}$ for the $\mathrm{GLBs}$ and from 70 to $85 \mathrm{dBA}$ for the BLBs. Sound levels at 50 feet were consistent with manufacturer ratings. At distances of 100 to 400 feet, $L_{90}$ levels were 4-22 dBA higher for GLBs than for BLBs. The measured GLB sound spectrum had a markedly greater low frequency component compared with the BLB sound spectrum allowing it to transmit and remain audible over longer distances and have greater adverse impact on the surrounding community. Further, the low frequency component of GLBs enabled their sound to transmit more readily through windows and glass doors of homes. Application of a measure of loudness as perceived by the human ear suggests that GLBs can often be heard up to several times louder than BLBs in outdoor and indoor settings. In actual settings, the routine use of multiple GLBs and other noisy equipment for hours a day exposes not only workers but large numbers of people in the community to harmful levels of noise and threatens not only work health, but public health, particularly of children, seniors, and other vulnerable populations. Policy makers and industry should adopt new technologies and good practices that place the health and well-being of workers and the public first.
\end{abstract}

Keywords: Noise; Lawn and garden equipment; Leaf blower; Community; Low frequency; Occupational health; Health effects

\section{Introduction}

Noise from commercial gas-powered leaf blowers (GLBs) is adversely affecting the lives of workers and citizens in communities in North America and other parts of the world. Approximately 170 communities in the United States have enacted some form of restriction on this specific piece of equipment. Originally developed to spray insecticide, GLBs today are used for a wide variety of outdoor tasks ranging from the actual blowing of leaves to hardscape cleaning, gutter cleaning, and even snow removal. The current dependence of the commercial land care industry on GLBs to perform tasks large and small has resulted in their ubiquitous presence in neighborhoods, parks, schools, and other public spaces.

Advances in electric battery technology are enabling a transition away from GLBs as well as other gas-powered equipment, including mowers, trimmers, and chain saws. Policy makers considering battery electric powered leaf blowers (BLBs) as possible alternatives presume them to be less harmful because of the elimination of emissions and less noise. However, there is a scarcity of objective data directly comparing the measured sound levels and spectra of operational GLBs and BLBs.

The objectives of this study are to: 1) compare in a head-to-head study the characteristics of sound from of commercial grade GLBs and BLBs in outdoor and indoor settings; 2) compare the impacts of GLB and BLB sound on communities; and 3) determine if GLBs and BLBs with the same manufacturer sound rating affect communities in the same way.

\section{Materials and Methods}

\section{Area and conditions of study}

Outdoor field work for this study was carried out on Sunday, June 18,2018 , between the hours of $10 \mathrm{am}$ and $3 \mathrm{pm}$ at the Department of Public Works, Lincoln, MA. The date was intentionally chosen for 
optimal weather (fair, little wind) and ambient sound conditions (less traffic, fewer trains). Lincoln is a suburb located approximately 20 miles from the City of Boston with a population of 8,600 (including residents of an air force base) and a land area approximating 15 square miles. The blowers were operated at a single location on pavement (the origin, blue asterisk on Outdoor Study Map-Figure 1) at more than 100 feet from any building, within 10 feet of a grassy area, and more than 400 feet from main town roads, as recommended by the American National Standards Institute (ANSI) [1]. Indoor measurements were taken at a nearby residential property $(0.6$ acre) with modern double pane insulated glass windows.

\section{Lawn and garden equipment}

Three models of commercial grade backpack GLBs and four models of the most powerful commercial grade backpack BLBs on the market were tested (Table 1). Two of the gas models were powerful, top-rated models used routinely in commercial landscape use [2]; the third (Echo PB760) was chosen because it is among those touted as "quiet GLBs" with the same manufacturer sound rating (A-weighted decibels [dBA] at 50 feet) as two of the BLBs. The ages of the machines ranged from new to three years. The fuel levels of the three GLBs were approximately 48 ounces at the start of the study. Each GLB and BLB was operated by the same person, an experienced lawn care/ landscaping professional.

\section{Sound measurement}

Sound measurements were made using a calibrated Type 1 professional sound level meter (Bruel and Kjaer type 2250 with windscreen and tripod mounted) capable of recording up to 140 $\mathrm{dBA}$ or $143 \mathrm{C}$-weighted decibels (dBC) across each of the $1 / 3$ octave band filters. A Type 1 meter ensures a high level of accuracy and repeatability.

\section{Sound metrics}

The primary metric was the $\mathrm{L}_{90}$, measured as an average and by $1 / 3$ octave band center frequency. An $\mathrm{L}_{90}$ is the sound energy (measured in $\mathrm{dBA}$ ) which is exceeded more than $90 \%$ of the time. Other metrics included: the $\mathrm{L}_{\mathrm{EQ}}$ which is the average equivalent $\mathrm{dBA}$ level and minimum $\left(\mathrm{L}_{\text {min }}\right)$ and maximum $\left(\mathrm{L}_{\text {max }}\right)$ sound levels taken on fast and slow settings. Compared with unweighted decibels $(\mathrm{dB})$, the dBA under weights the contribution of lower frequency sound. Compared with the $\mathrm{L}_{\mathrm{EQ}}$ which is an average, the $\mathrm{L}_{90}$ is a more conservative measure of sound level representing a lower threshold that more confidently captures the GLB/BLB sound rather than traffic sound. The $\mathrm{L}_{90}$ metric, enables the measurements to confidently represent the GLB/BLB noise when there may also be fluctuating ambient noise levels present.

\section{Outdoor measurements}

The machines were tested at distance intervals of 5, 50, 100, 200, 400 , and 800 feet in a straight line from the origin as shown in figure 1. ANSI's Safety Requirements and Performance Testing Procedures for blowers [3] were used to guide sound testing at the origin and at $50 \mathrm{feet}$. At all distances, the microphone was positioned four feet above the ground. In every case, operators brought the blowers immediately to full power once started. At each distance interval, a thirty second ambient sound measurement was taken to account for background noise, e.g., road traffic. In instances in which loud sound from external sources (e.g. train, plane, siren) interfered, measurements were repeated.

Measurements at the origin and at fifty feet: Sound at the origin was measured five feet from the operator for 30 seconds. At 50 feet, the operators ran the blowers at eight positions $\left(0^{\circ}, 45^{\circ}, 90^{\circ}, 135^{\circ}, 180^{\circ}\right.$, $225^{\circ}, 270^{\circ}$, and $315^{\circ}$ to the axis), rotating in a circle in a clockwise direction in accordance with ANSI standards [3]. The operator held the blower tube in normal operating position with the end of the blower tube (nozzle) at least 2 inches from the surface and maintained a consistent blower tube position throughout the rotation. At each position, the sound was measured for 30 seconds. For comparison with pavement, a 30 second measurement was taken with the operator standing on a grass surface, using the blower as they would for routine maintenance work while rotating through 360 degrees.

Measurements at distances beyond 50 feet: For measurements at all further distances, the operator ran the blowers as if using them in routine maintenance while rotating through $360^{\circ}$ with sound measurements taken for one minute.

\section{Indoor sound measurements}

At the residential property, blowers were operated at full power in the backyard 50 feet from an insulated, double pane glass window. The operator stood on natural ground cover (grass, ivy) and operated the blower at full power and as they would for routine maintenance while rotating through $360^{\circ}$. Sound measurements were taken for one minute indoors within five feet of the closed window. All windows and doors of the home were closed while sound measurements were taken.

\section{Analyses}

All analyses were performed using descriptive statistics. At 50 feet, an average of the $\mathrm{L}_{90}$ was derived from the $\mathrm{L}_{90}$ at each of the eight positions of the circle. The minimum difference in $\mathrm{L}_{90}$ between GLBs and BLBs was calculated as the smallest difference between values from each type; the maximum difference was calculated as the greatest difference between values from each type. The relative loudness of sound from GLBs and BLBs as perceived by the human ear was calculated using the following standards: A $3 \mathrm{~dB}$ difference is noticeable to the human ear; a difference of $10 \mathrm{~dB}$ less reduces the perceived sound by $50 \%$ and a difference of $10 \mathrm{~dB}$ more doubles the perceived sound. In a nested comparison, the loudness of sound over distance for the Echo GLB (manufacturer-rated at $65 \mathrm{dBA}$ ) was compared with the BLBs that were manufacturer-rated at 64-65 dBA.

\section{Results}

\section{Outdoors: Sound energy and perceived loudness}

At 5 feet and 50 feet, the observed sound levels from the GLBs were consistent with available manufacturer noise ratings using ANSI standards (Table 2). The $\mathrm{L}_{90}$ of the quietest GLB, the Echo PB760, at 5 and 50 feet were comparable to three of the BLBs. At both distances, the $\mathrm{L}_{90}$ of the two louder GLBs (Redmax, Stihl) were 8-20 dBA higher than those of the BLBs, indicating that the perceived loudness was approximately double that of the GLBs.

At distances of 100, 200, and 400 feet, the measured sound level is higher for the GLBs compared with the BLBs (Table 3). The two more powerful GLBs (Redmax, Stihl) were 7-22 dBA higher than the BLBs, meaning the perceived loudness was two to more than 4 times higher. The quieter GLB (Echo) was 3-13 dBA higher compared with the BLBs, meaning the difference in sound level was noticeable to more than twice as loud. At 800 feet, the differences in audible sound profile narrowed considerably. However, it was observed that the three GLB were still audible, two being clearly audible and the third being less audible, but still noticeable.

\section{Outdoors: Sound energy and frequency}

The loudness and frequency profiles of GLBs and BLBs at all distances are shown in figures 2-7. Most outdoor measurements in 
Table 1: Summary of Equipment.

\begin{tabular}{|c|c|c|c|c|}
\hline \multirow{2}{*}{ Make/Model } & Power Source & Max Air Flow & Max Air Speed & \multirow{2}{*}{$\begin{array}{l}\text { ANSI Manufacturer Sound } \\
\text { Rating at } 50 \text { feet (dBA)[3] }\end{array}$} \\
\hline & & (CFM) $^{*}$ & (MPH) ${ }^{*}$ & \\
\hline Redmax EBZ8500 & Gasoline & 908 & 206 & 77 \\
\hline Stihl BR 700x & Gasoline & 901 & 193 & 75 \\
\hline Echo PB760 & Gasoline & 535 & 214 & 65 \\
\hline Greenworks GBB 700 & Lithium battery & $640-700$ & $160-170$ & N/A \\
\hline Greenworks GBB 600 & Lithium battery & 600 & 150 & 64 \\
\hline Chervon EGO 600 & Lithium battery & 580 & 168 & 65 \\
\hline Stihl BGA 100 & Lithium battery & 494 & 168 & 56 \\
\hline
\end{tabular}

Table 2: Measured Operational Sound Levels of Equipment at 5 Feet and 50 Feet (Outdoors).

\begin{tabular}{|c|c|c|c|c|}
\hline \multirow{2}{*}{ Make/Model } & \multirow{2}{*}{ Type } & \multirow{2}{*}{$\begin{array}{l}\text { ANSI Manufacturer Sound } \\
\text { Rating at } 50 \text { Feet (dBA)[3] }\end{array}$} & \multicolumn{2}{|c|}{ Measured $L_{90}$ dBA } \\
\hline & & & At 5 Feet & At 50 Feet \\
\hline Redmax EBZ8500 & GLB & 77 & $93 * *$ & 77 \\
\hline Stihl BR 700x & GLB & 75 & 90 & 77 \\
\hline Echo PB760 & GLB & 65 & 82 & 67 \\
\hline Greenworks GBB 700 & BLB & N/A & 85 & 67 \\
\hline Greenworks GBB 600 & BLB & 64 & 83 & 64 \\
\hline Chervon EGO 600 & BLB & 65 & 77 & 64 \\
\hline Stihl BGA 100 & BLB & 56 & 70 & 57 \\
\hline \multicolumn{2}{|c|}{ Range of difference in sound pressure levels (dBA): GLB vs BLB } & 0 to 21 & 1 to 23 & 0 to 20 \\
\hline \multicolumn{2}{|c|}{ Relative difference in perceived loudness: GLB vs BLB } & 0 to 4 times louder & 0 to 4 times louder & 0 to 4 times louder \\
\hline
\end{tabular}

Table 3: Measured Operational Sound Levels of Equipment at 100, 200, 400, and 800 Feet (Outdoors).

\begin{tabular}{|c|c|c|c|c|c|}
\hline \multirow{2}{*}{ Make/Model } & \multirow{2}{*}{ Type } & \multicolumn{4}{|c|}{ Measured $\mathrm{L}_{90} \mathrm{dBA}$} \\
\hline & & At 100 Feet & At 200 Feet & At 400 Feet & At 800 Feet \\
\hline Redmax EBZ8500 & GLB & 71 & 66 & 55 & 39 \\
\hline Stihl BR 700x & GLB & 72 & 65 & 58 & 39 \\
\hline Echo PB760 & GLB & 63 & 56 & 48 & 37 \\
\hline Greenworks GBB 700 & BLB & 59 & 52 & 44 & 36 \\
\hline Greenworks GBB 600 & BLB & 57 & 46 & 41 & 39 \\
\hline Chervon EGO 600 & BLB & 57 & 49 & 45 & 41 \\
\hline Stihl BGA 100 & BLB & 50 & 44 & 38 & 34 \\
\hline \multicolumn{2}{|c|}{$\begin{array}{l}\text { Range of difference in sound pressure levels (dBA): } \\
\qquad \text { GLB vs BLB }\end{array}$} & 4 to 22 & 4 to 22 & 3 to 20 & -4 to 5 \\
\hline \multicolumn{2}{|c|}{ Relative difference in perceived loudness: GLB vs BLB } & $\begin{array}{l}\text { Noticeably louder to } \\
4 \text { times louder }\end{array}$ & $\begin{array}{l}\text { Noticeably louder to } 4 \\
\text { times louder }\end{array}$ & $\begin{array}{l}\text { Noticeably louder to } \\
4 \text { times louder }\end{array}$ & $\begin{array}{c}\text { Noticeably above } \\
\text { ambient vs. not } \\
\text { audible }\end{array}$ \\
\hline
\end{tabular}




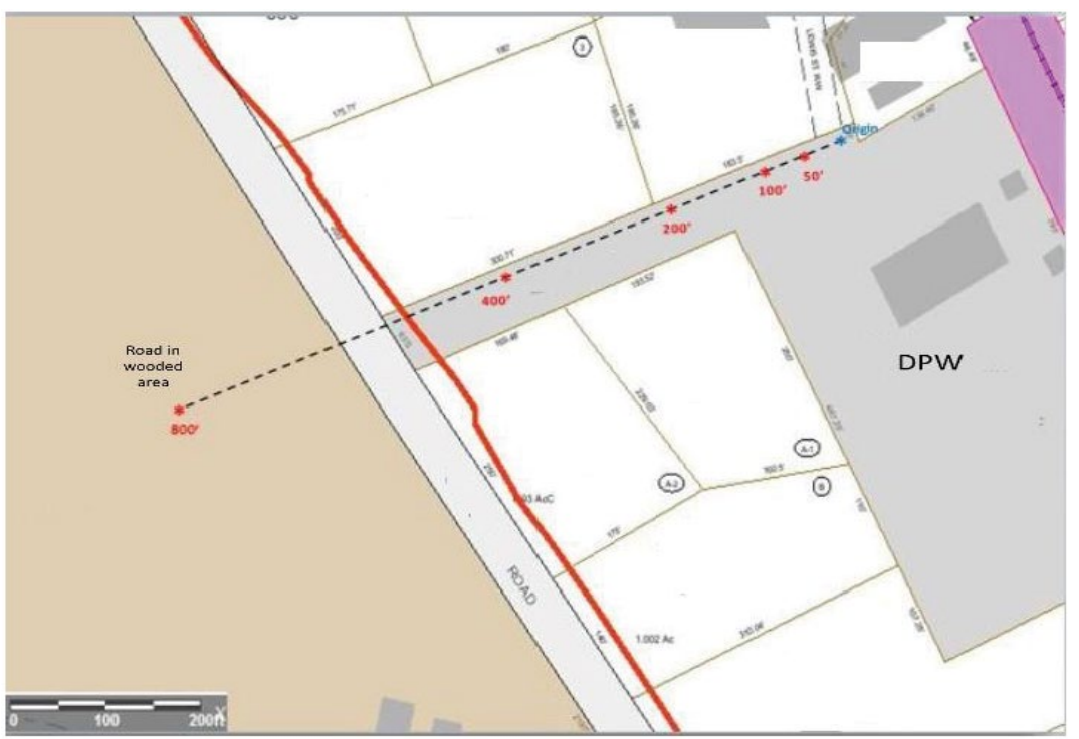

Figure 1: Map of Area for Outdoor Measurements.

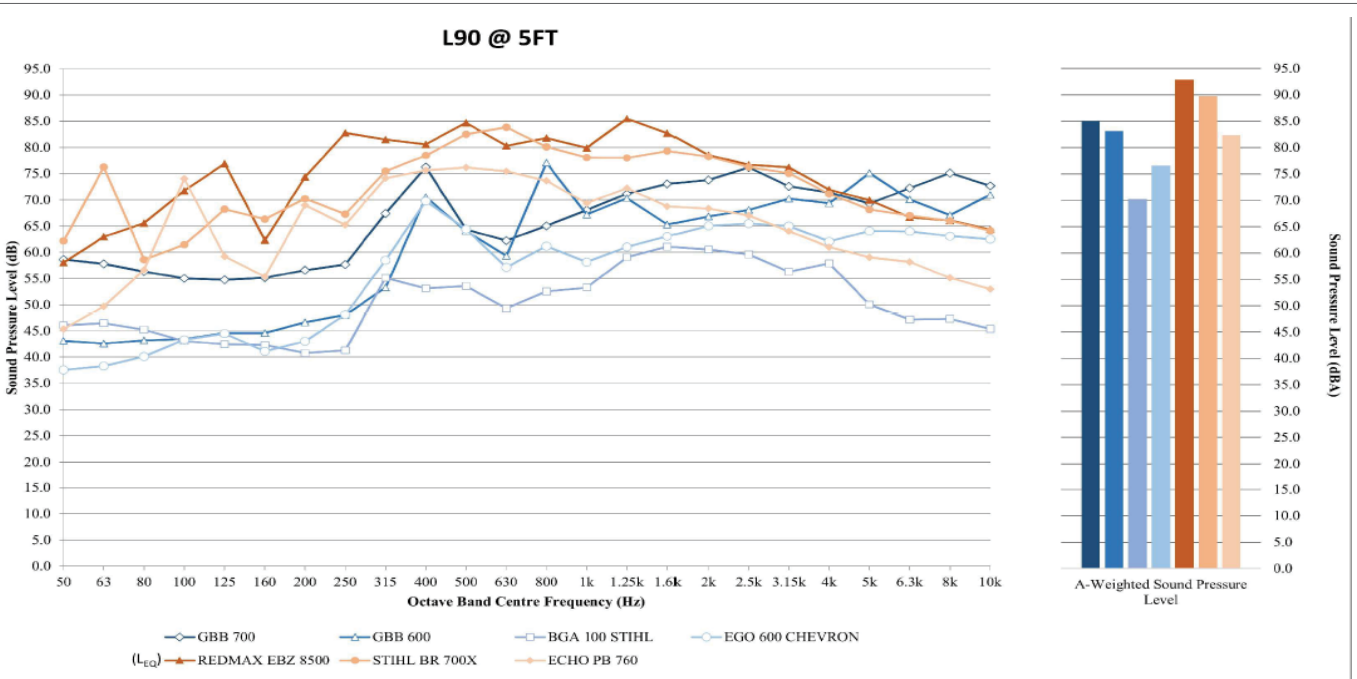

Figure 2: $L_{90}$ Measurements for GLB and BLB Models at 5 Feet.

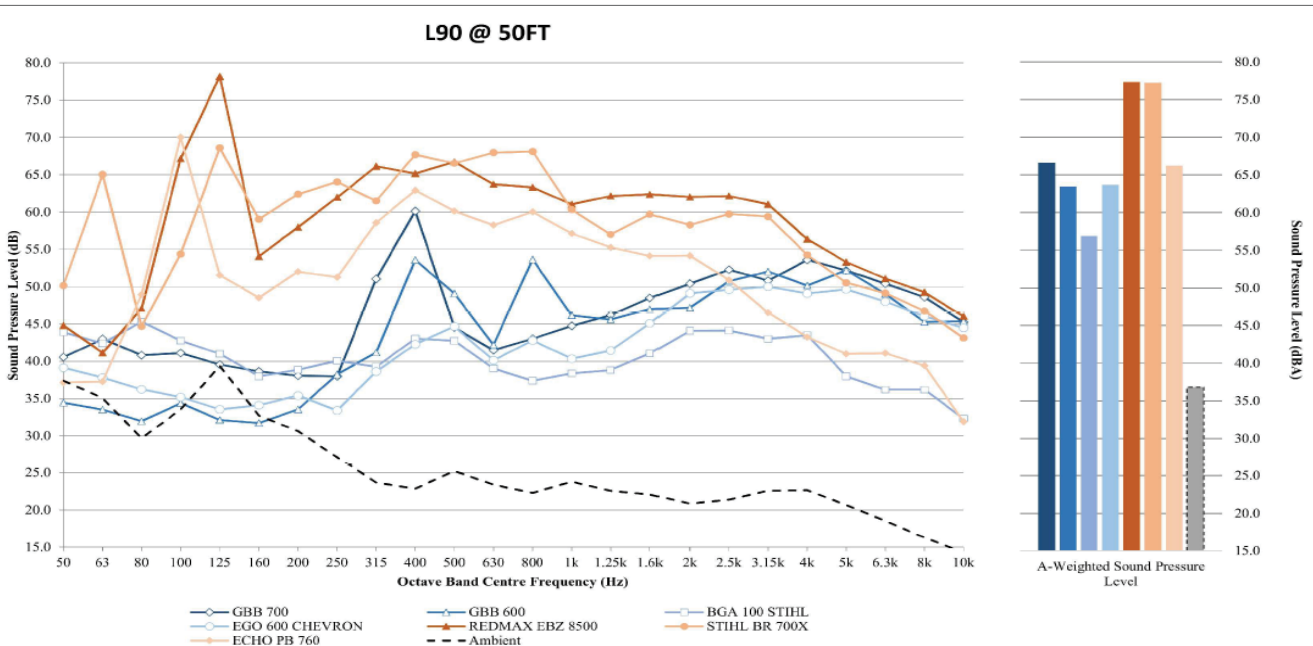

Figure 3: $L_{90}$ Measurements for GLB and BLB Models at 50 Feet. 


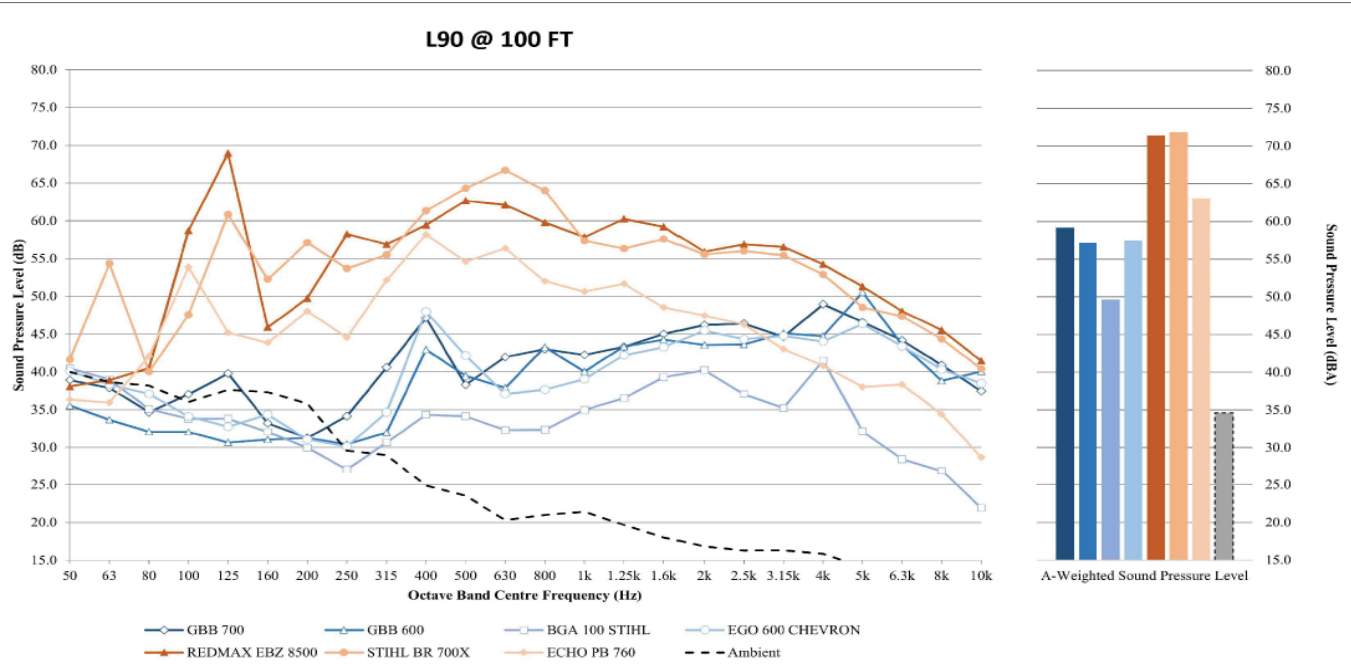

Figure 4: $L_{90}$ Measurements for GLB and BLB Models at 100 Feet.
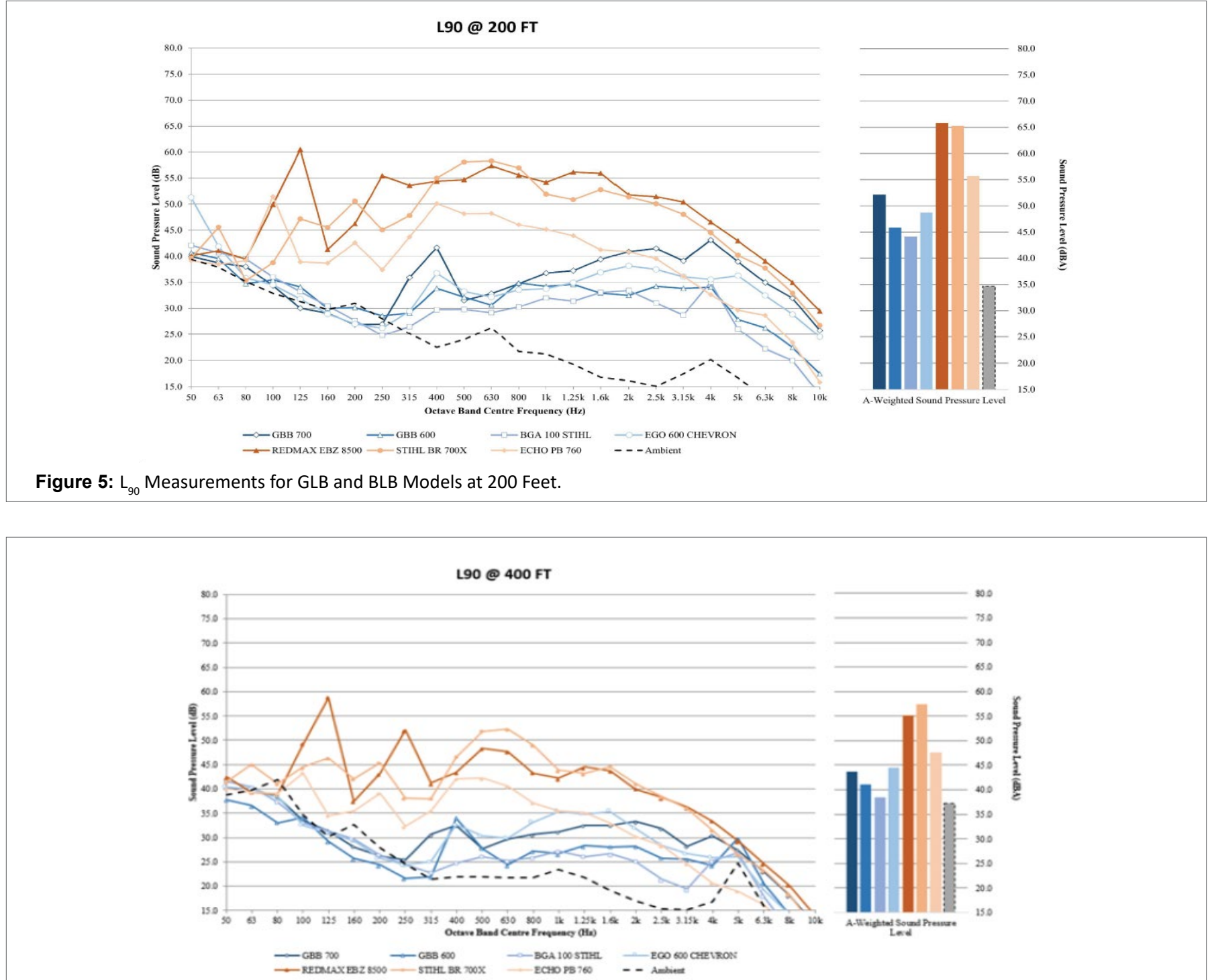

Figure 6: $\mathrm{L}_{90}$ Measurements for GLB and BLB Models at 400 Feet. 


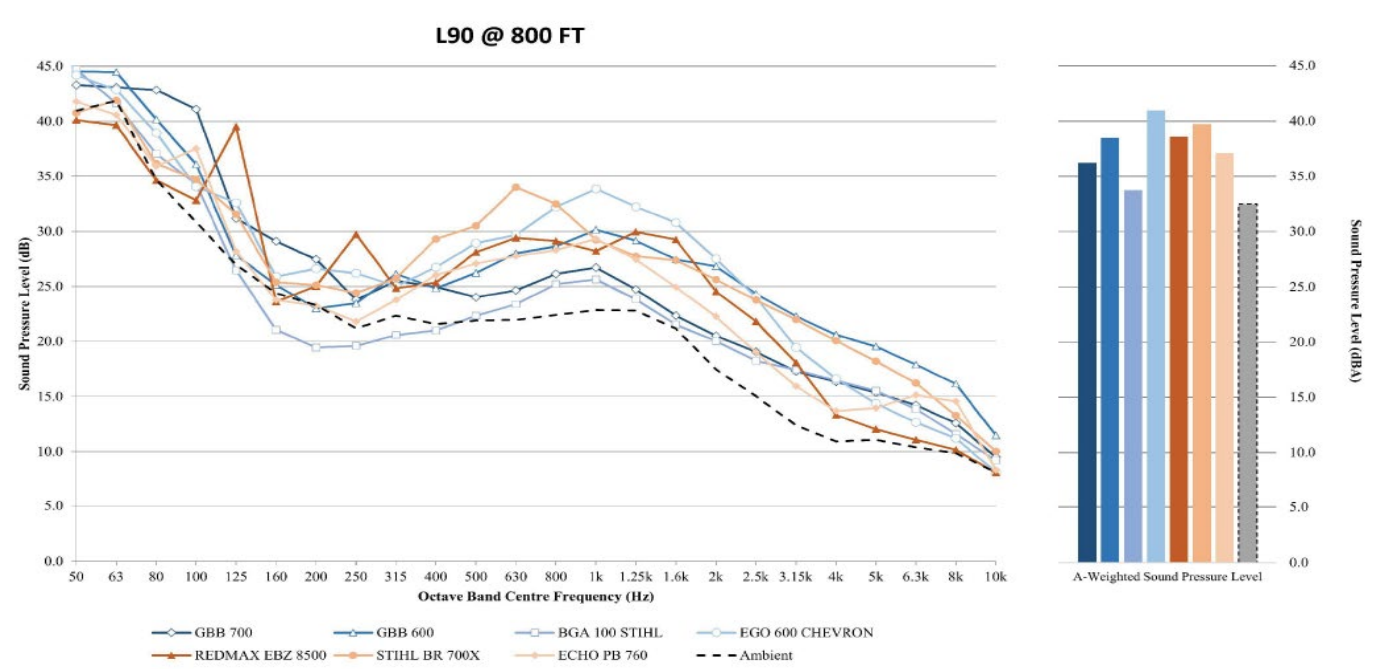

Figure 7: $L_{90}$ Measurements for GLB and BLB Models at 800 Feet.

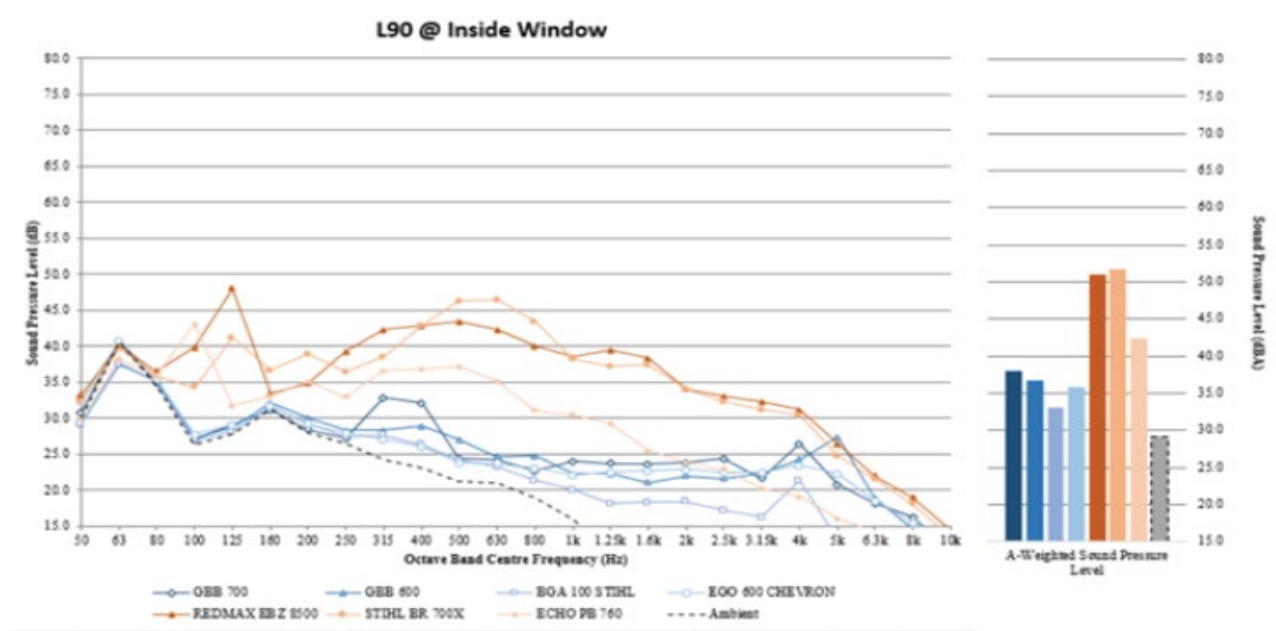

Figure 8: $L_{90}$ Measurements for GLB and BLB Models inside Window.

locations with any distant traffic will have more low frequency than high frequency noise, and the ambient sound in this study was also of this character. At distances of more than 5 feet and less than 800 feet, the frequency profiles of GLBs and BLBs are markedly divergent. The GLBs (shaded in orange) produced much higher levels of sound energy in the low frequency bands at all distances compared with the BLBs. In a number of cases, this sound peaked at 100 to $125 \mathrm{~Hz}$. These differences became most marked at distances of 100 to 400 feet.

Although at 800 feet, there were negligible differences in $L_{90}$ between the GLBs and BLBs, it was observed that the three GLB were still audible, two being clearly audible and the third being noticeable. In contrast, the sound energies from the BLBs were indistinguishable from the ambient sound level at that distance. Only the peaks of low frequency sound from the GLBs were prominently audible above the ambient noise. Because these low frequency peaks do not occur with the BLBs, it is this low frequency component that is likely to account for the audibility of the GLBs over long distances.

\section{Indoor measurements}

Table 4 shows that differences in sound measured indoors ranged from 5-19 dBA higher for GLB compared with BLB, meaning that in most cases the perceived sound from the GLBs compared with the BLBs was clearly noticeably louder, and in some cases, up to four times as loud. As seen in figure 8 , the low frequency sound $(100-125 \mathrm{~Hz}$ as well as frequencies up to around $500 \mathrm{~Hz}$ ) from GLBs, as measured inside the house, were significantly above those of the BLBs.

\section{Nested comparison of GLB and BLB with comparable manufacturer noise ratings}

Outdoor measurements (Table 5) showed differences in sound levels from the GLB (Echo PB 760) and two BLBs (with similar manufacturer noise ratings of 64-65 dBA at 50 feet) over distances up to 400 feet. Human perceived loudness was up to two to four times greater for the GLB at distances up to 400 feet.

Indoor measurements (Table 6) showed differences in sound levels that would be perceived as noticeably louder to twice as loud 
for the GLB compared with the BLBs.

\section{Discussion}

This is the first published study to directly compare the measured characteristics of commercial grade GLB and BLB sound over distance, in outdoor and indoor community settings. It found that a strong low frequency component is responsible for transmitting more audible GLB sound over long distances and into homes, consistent with the findings of previous studies [4,5] and with what is generally known about internal combustion engine sound $[6,7]$. The study also determined that people experience GLBs as much louder than BLBs at distances up to at least 400 feet outdoors, and indoors as well, even when the GLB and BLB have the same manufacturer noise rating.

Commercial landscape maintenance activities have become a major source of air pollution as well as of environmental noise. The GLB is often cited as the most egregious source of harmful noise [8-10].

At the ear of the operator, GLB sound exceeds the $85 \mathrm{dBA}$ occupational safety standard set by NIOSH (National Institute of Occupational Safety and Health) by 10-to 100 -fold $[2,11]$. At 50 feet, it far exceeds the World Health Organization's 55 dBA outdoor noise guideline and 35-45 dBA indoor noise guideline to protect the health of the public [12-14]. With GLBs, the low frequency sound component is what is most easily transmitted and is what accounts for its audibility over long distances as well as inside homes and structures. One of the challenges with low frequency noise is that it requires heavy construction or materials to reduce the sound transmitting. This is very clear when it comes to windows and glass doors in houses. The heavy drywall or brick walls of a house may do a good job at blocking noise from outside, but low frequency sound transmits more easily through the lighter weight windows. This is a common issue with the drone of road traffic or aircraft overhead, and several states and federal programs (e.g., the FAA Airport Noise Program/Residential Sound Insulation Program administered by the US CDC) provide funding to upgrade housing in impacted areas.

Regular exposure to loud and/or persistent noise contributes to hearing impairment, hypertension, ischemic heart disease, annoyance, sleep disturbance, cognitive impairment, and diminished school performance [15-17]. Noise over 60 decibels increases the risk of cardiovascular disease [15]. Low frequency noise is a special health concern because it may "increase adverse effects considerably"

Table 4: Measured Operational Sound Levels of Equipment Indoors.

\begin{tabular}{|c|c|c|}
\hline Make/Model & Type & Measured $L_{90} d B A$ \\
\hline Redmax EBZ8500 & GLB & 51 \\
\hline Stihl BR 700x & GLB & 52 \\
\hline Echo PB760 & GLB & 43 \\
\hline Greenworks GBB 700 & BLB & 38 \\
\hline Greenworks GBB 600 & BLB & 37 \\
\hline Chervon EGO 600 & BLB & 36 \\
\hline Stihl BGA 100 & BLB & 33 \\
\hline \multicolumn{2}{|c|}{$\begin{array}{l}\text { Range of difference in sound pressure levels } \\
\qquad(\mathrm{dBA}) \text { : GLB vs BLB }\end{array}$} & 5 to 19 \\
\hline \multicolumn{2}{|c|}{$\begin{array}{l}\text { Relative difference in perceived loudness: GLB } \\
\qquad \text { vs BLB }\end{array}$} & $\begin{array}{l}\text { Noticeably louder } \\
\text { to } 4 \text { times louder }\end{array}$ \\
\hline
\end{tabular}

BLB: Battery-powered leaf blower; GLB: Gas-powered leaf blower
$[12,18]$. Studies in animals show that exposure to low frequency noise causes fibrosis and thickening of cardiovascular vessels $[19,20]$. Populations most vulnerable to these effects include not only the equipment operators, but also children, seniors, people with hearing disorders and neurological conditions like autism and sensory deficit disorders [21].

Use of GLBs and other noisy landscape maintenance equipment is unregulated. Industry guidelines (e.g., only one GLB in use at a time, never operated at full throttle in residential settings, never operated within fifty feet of people) are routinely disregarded by operators and business owners. Rather, these blowers are often part of a stable of equipment used for maintenance that may include mowers, edgers, trimmers, and saws. The combination of all this equipment and their distribution around a property can produce sound that has a much greater impact on a community than a single piece of equipment. Although not considered here, it must be mentioned that these machines are not only a source of harmful noise, but also of emissions, including ozone - forming chemicals, carbon monoxide, and fine particulates.

The number of households affected by harmful levels of noise depends on several factors. Ameliorating factors include high levels of ambient noise, structures and natural barriers. Exacerbating factors may include the combined use of multiple pieces of equipment. In quieter neighborhoods where GLB sound is not masked by other sources, the degree of community impact will rely largely on the distance over which harmful noise levels are transmitted. The area of impact is a function of the square of this distance, meaning that even a small increase in the distance over which harmful levels of sound are transmitted can have a large adverse impact on the community.

The results of this study provide a conservative estimate of harmful noise exposure from gas-powered landscape maintenance practices. They do not represent common situations in which people living in densely populated neighborhoods are exposed to the sound from several GLBs and other equipment operating on a single property and/ or multiple properties for hours at a time several days each week. In this situation, harmful levels of protracted noise may carry out to 400 or more and may affect more than 90 households.

Good landscape maintenance practices should be as much about health and quality of life, as they are about aesthetics. Policy makers and industry players - manufacturers and service providers - need to recognize that the unbridled use of GLBs and other noisy equipment has become a public health problem in some communities, threatening the health and well-being of the public, particularly children, seniors, and other vulnerable populations. While BLBs are not perfect with regard to noise, they constitute a major improvement and are now powered so that they can be used for all routine commercial tasks. Transitioning to BLBs as well as other battery electric equipment would reduce health risks for operators from noise (and from toxic emissions) and improve the health and well-being of entire neighborhoods.

Lastly, it should be noted that the ANSI dBA standard at 50 feet does not adequately evaluate community impact or allow comparisons of gas-and battery-powered equipment sound and has been widely criticized in its application to internal combustion engines [12,18, 2225]. Because it underweights the contribution of low frequency sound, it does not provide information sufficient to evaluate how sound energy transmits over distance or on its related health risks. More appropriate measures are needed. 
Table 5: Measured Operational Sound Levels of Equipment with Equivalent Manufacturer Sound Ratings at Distances of 5 Feet to 800 Feet (Outdoors).

\begin{tabular}{|c|c|c|c|c|c|c|c|}
\hline \multirow{2}{*}{ Make/Model } & \multirow{2}{*}{ Type } & \multicolumn{6}{|c|}{ Measured $\mathrm{L}_{90} \mathrm{dBA}$} \\
\hline & & $5 \mathrm{ft}$ & $50 \mathrm{ft}$ & $100 \mathrm{ft}$ & $200 \mathrm{ft}$ & $400 \mathrm{ft}$ & $800 \mathrm{ft}$ \\
\hline Echo PB760 & GLB & 82 & 67 & 63 & 56 & 48 & 37 \\
\hline Greenworks GBB 600 & BLB & 83 & 64 & 57 & 46 & 41 & 38 \\
\hline Chervon EGO 600 & BLB & 77 & 64 & 57 & 49 & 45 & 41 \\
\hline \multicolumn{2}{|c|}{$\begin{array}{l}\text { Range of difference in sound pressure } \\
\text { levels (dBA): GLB vs BLB }\end{array}$} & -1 to 5 & 3 & 6 & 7 to 10 & 3 to 7 & -1 to -4 \\
\hline \multicolumn{2}{|c|}{$\begin{array}{l}\text { Relative difference in perceived } \\
\text { loudness: GLB vs BLB }\end{array}$} & $\begin{array}{c}\text { Similar to Noticeably } \\
\text { louder }\end{array}$ & $\begin{array}{l}\text { Noticeably } \\
\text { louder }\end{array}$ & $\begin{array}{l}\text { Noticeably } \\
\text { louder }\end{array}$ & $\begin{array}{l}\sim 2 \text { times } \\
\text { louder }\end{array}$ & $\begin{array}{l}\text { Noticeably } \\
\text { louder }\end{array}$ & Similar \\
\hline
\end{tabular}

Table 6: Measured Sound Levels of Equipment with Equivalent Manufacturer Sound Ratings (Indoors).

\begin{tabular}{|l|c|c|}
\hline \multicolumn{1}{|c|}{ Make/Model } & Type & Measured $\mathbf{~}_{\mathbf{9 0}} \mathbf{~ d B A ~}$ \\
\hline Echo PB 760 & GLB & 43 \\
\hline Greenworks GBB 600 & BLB & 37 \\
\hline Chervon EGO 600 & BLB & 36 \\
\hline $\begin{array}{l}\text { Range of difference in sound pressure levels } \\
\text { (dBA): GLB vs BLB }\end{array}$ & $6-7$ \\
\hline $\begin{array}{l}\text { Relative difference in perceived loudness: GLB } \\
\text { vs BLB }\end{array}$ & $\begin{array}{l}\text { Noticeably louder } \\
\text { to 2 times louder }\end{array}$ \\
\hline BLB: Battery-powered leaf blower; GLB: Gas-powered leaf blower
\end{tabular}

BLB: Battery-powered leaf blower; GLB: Gas-powered leaf blower

\section{Conclusions}

GLBs affect many people with harmful levels of noise, known to cause serious health problems. The proliferation of GLBs along with other noisy pieces of gas-powered equipment are creating a public health problem in communities, exposing large numbers of people to harmful noise, including children and others who are especially vulnerable. Policy makers should raise public awareness of GLB and other gas-powered landscape equipment as local sources of harmful noise, as well as toxic emissions. Industry-manufacturers and service providers-should adopt equipment and practices that place the highest priority on the health of workers and the public.

\section{Acknowledgements}

The authors would like to thank the Department of Public Works, Town of Lincoln, MA, EcoQuiet Lawn Care, Concord, MA, Pumpkin Brook Organic, Shirley, MA, and Rebecca Reibstein for their assistance.

\section{Funding sources}

This study was supported by private donations.

\section{Conflicts of Interest}

The authors declare no conflict of interests.

\section{References}

1. American National Standards Institute, Inc. (1994) American National Standard. Procedures for Outdoor Measurement of Sound Pressure Level. ANSI S12.18-1994, Acoustical Society of America, Melville, NY.
2. Johnson T (2017) Leaf blower reviews: Best backpack blower shootout. OPE Reviews. December 29. Accessed October 2018.

3. Section 9 in American National Standard for Outdoor Power Equipment-Internal Combustion Engine-Powered Handheld and Backpack Blowers and Blower-Vacuums-Safety Requirements and Performance Testing Procedures (2012) American National Standards Institute, Inc. ANSI/OPEI B175.2-2012, including Amendment 1 ANSI/OPEI B175.2-2012/A1-2013.

4. Walker E, Banks JL (2017) Characteristics of Lawn and Garden Equipment Sound: A Community Pilot Study. J Environ Toxicol Stu 1.

5. Pasanen T, Rytkonen E, Sorainen E (2004) Leaf Blower Noise. Joint Baltic-Nordic Acoustics Meeting 2004, 8-10 June 2004, BNAM20042Mariehamn, Åland.

6. Zheng GT, Leung AYT (2002) Internal Combustion Engine Noise Analysis with Time-Frequency Distribution. J Eng Gas Turbine Power 124: 645-649.

7. Roberts C (2010) Low Frequency Noise from Transportation Sources. Proceedings of 20th International Congress on Acoustics, ICA 2010, 23-27 August 2010, Sydney, Australia.

8. US Centers for Disease Control and Prevention (2017) Too Loud! For Too Long! CDC Vital Signs, February. Accessed October 2018.

9. National Institute on Deafness and Other Communication Disorders (2014) NICDC Fact Sheet. Noise-Induced Hearing Loss. NIH Pub. No. 99-4233, March 2014, Reprinted July 2016. Accessed October 2018.

10. US Environmental Protection Agency (2009) Noise and Its Effects on Children. Washington, DC. 20460 EPA-410-F-09-003, November. Accessed on October 2018.

11. How Do We Protect Our Ears? A Hearing Conservation Program of PLANET (Professional Landcare Network).

12. Berglund B, Lindvall T, Schwela DH (1999) Guidelines for Community Noise. World Health Organization, Geneva, Switzerland.

13. Information on Levels of Environmental Noise Requisite to Protect Public Health and Welfare with an Adequate Margin of Safety (1974) US Environmental Protection Agency, March, Publication 550/9-74004, Washington, DC.

14. Fink DJ (2017) What Is a Safe Noise Level for the Public? Am J Public Health 107: 44-45.

15. Münzel T, Schmidt FP, Steven S, Herzog J, Daiber A, et al. (2018) Environmental Noise and the Cardiovascular System. J Am Coll Cardiol 71: 688-697.

16. Basner M, Babisch W, Davis A, Brink M, Clark C, et al. (2014) Auditory and non-auditory effects of noise on health. Lancet 383: 1325-1332. 
17. Kempen EV, Casas M, Pershagen, Foraster M (2018) WHO Environmental Noise Guidelines for the European Region: A Systematic Review on Environmental Noise and Cardiovascular and Metabolic Effects: A Summary. Int J Environ Res Public Health 15: E379.

18. Berglund B, Hassmen B, Job R (1996) Sources and effects of lowfrequency noise. J Acoust Soc Am 99: 2985-3002.

19. Fonseca J, Martins-dos-Santos J, Oliveira P, Laranjeira N, Aguas A, et al. (2012) Noise-induced gastric lesions: a light and electron microscopy study of the rat gastric wall exposed to low frequency noise. Arq Gastroenterol 49: 82-88.

20. Antunes E, Borrecho G, Oliveira P, Alves de Matos AP, Brito J, et al. (2013) Effects of low-frequency noise on cardiac collagen and cardiomyocyte ultrastructure: an immunohistochemical and electron microscopy study. Int J Clin Exp Pathol 6: 2333-2341.
21. Kanakri SM, Shepley M, Varni JW, Tassinary LG (2017) Noise and autism spectrum disorder in children: An exploratory survey. Res Dev Disabil 63: 85-94.

22. Committee on Technology for a Quieter America (2010) Technology for a Quieter America. National Academies Press, Washington, DC.

23. I-INCE (2015) Supplemental Metrics for Day-Night Average Sound Level and Day-Evening-Night Average Sound Level: Final Report of the Technical Study Group on Metrics for Environmental Noise Assessment and Control. Retrieved October 2018.

24. Leventhall HG (2004) Low frequency noise and annoyance. Noise Health 6: 59-72.

25. Persson, K, Björkman M, Rylander R (1990) Loudness, Annoyance and dBA in Evaluating Low Frequency Sounds. J Low Freq Noise Vibn 9: 32-45. 